\title{
Improving hydrodynamic performance of waste stabilisation ponds using three-dimensional numerical models
}

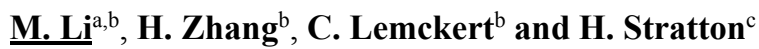 \\ ${ }^{a}$ Engineering Building 1300, Charles Sturt University, Panorama Avenue, Bathurst, NSW, 2795, Australia \\ ${ }^{b}$ Griffith School of Engineering, Griffith University, Gold Coast campus, QLD 4222, Australia \\ ${ }^{c}$ School of Biomolecular and Physical Sciences, Griffith University, Nathan Campus, QLD 4111, Australia \\ Email:
}

\begin{abstract}
Waste stabilisation ponds (WSPs) are widely used for wastewater treatment throughout the world. They are shallow constructed basins, typically located at the end of a treatment plant, that use natural microbiological, photosynthetic, biochemical, physico-chemical and hydrodynamic processes to generate a reduction of organic matters and pathogenic organisms in wastewater (Watters et al., 1973). They require little technical attention during operation, and are less demanding in terms of construction cost and energy consumption than other engineered wastewater treatment systems.

Practical experience and research over the past few decades have established that hydrodynamics is one of the crucial factors determining WSP's overall treatment performance. The Department of Environment and Planning (1992) in the state of Tasmania surveyed 39 wastewater treatment systems and reported that $74 \%$ of the pond systems failed to achieve the discharge requirements, and it is due to the hydraulic problems including short-circuiting, stratification in hot Australian climates, and stagnant fluid in dead zones. Therefore, it is of primary importance that WSP's hydrodynamic performance be improved before WSP treatment efficiency can be guaranteed.
\end{abstract}

A substantial number of numerical modelling studies have been undertaken to look into WSP hydrodynamics, both two-dimensionally and three-dimensionally. It is the ultimate goal of this study to use numerical modelling techniques to investigate measures to improve WSP hydrodynamic performance, consequently to propose retrofitting design. A validated three-dimensional numerical model using MIKE 3 by DHI (Danish Hydraulic Institute) was developed to study a typical pond with a dimension of $50 \mathrm{~m}$ (length) by $20 \mathrm{~m}$ (width) by $1.5 \mathrm{~m}$ (depth). The retrofitting scheme was proposed by placing baffles in the pond with different geometric ratios: the ratio of baffle length $L_{b}$ to the width of the pond $W: L_{b} / W$, and the ratio of baffle spacing $\Delta_{b}$ to the length of the pond $L: \Delta_{b} / L$. For generalised design guidance, baffles positively contribute to the hydraulic efficiency for ponds with a relatively small $L / W$ ratio. Placing 8 baffles in a pond with $L / W=1.6$ results in a $\lambda$ (hydraulic efficiency) $=0.83$ as oppose to $\lambda=0.23$ if the pond is not baffled. However, ponds do not benefit from retrofitting baffles if their $L / W$ ratios are large.

Ultimately, this study is to provide regulators, decision makers, water managers and operators with information and tools to best operate and manage WSPs, to protect public and environmental health and optimise uses of the treated water.

Keywords: $\quad$ Waste stabilisation ponds, three-dimensional, hydraulic efficiency, retrofitting baffles 
Li et al., Improving hydrodynamic performance of waste stabilisation ponds using three-dimensional numerical models

\section{INTRODUCTION}

Waste stabilisation ponds (WSPs) are widely used for wastewater treatment throughout the world. They are shallow constructed basins, typically located at the end of a treatment plant, that use natural microbiological, photosynthetic, biochemical, physico-chemical and hydrodynamic processes to generate a reduction of organic matters and pathogenic organisms in wastewater (Watters et al., 1973). They require little technical attention during operation, and are less demanding in terms of construction cost and energy consumption than other engineered wastewater treatment systems.

Practical experience and research over the past few decades have established that hydrodynamics is one of the crucial factors determining WSP overall treatment performance. The Department of Environment and Planning (1992) in the state of Tasmania surveyed 39 wastewater treatment systems and reported that $74 \%$ of the pond systems failed to achieve the discharge requirements, and it is due to the hydraulic problems including shortcircuiting, stratification in hot Australian climates, and stagnant fluid in dead zones. Therefore, it is of primary importance that WSP hydrodynamic performance be improved before WSP treatment efficiency can be guaranteed.

A substantial number of studies have been undertaken to look into WSP's hydrodynamics, especially after the capacity of computational modelling was elevated in 1990s (Abbas et al., 2006; Alvarado et al., 2011; BadrotNico et al., 2009; Fares, 1993; Fares and Lloyd, 1995; Salter et al., 2000; Sweeney et al., 2005; Wood et al., 1995). It is the ultimate goal of this study to use numerical modelling techniques to investigate methods to improve WSP hydrodynamic performance, and to propose retrofitting design. Ultimately, this is to provide regulators, decision makers, water managers and operators with information and tools to best operate and manage WSPs, to protect public and environmental health and optimise uses of the treated water.

The reminder of the manuscript is organised as follows: the physical and mathematical formulations of WSP hydrodynamics and transport is introduced in Section 2. The configuration of the three-dimensional model is presented in Section 3. Measures of hydrodynamic behaviour of WSPs are explained in Section 4. It is followed by Section 5 to propose retrofitting design schemes by placing baffles in the pond. Section 6 concludes the paper by highlighting the main findings of this study and proposing guidelines for future work.

\section{PROBLEM FORMULATION}

\subsection{Physical configuration}

An example of a pond entity is illustrated in Figure 1 (a). It can be represented by a rectangular-shaped basin as shown in Figure 1 (b). $L, W$ and $D$ denote the length, width and the depth of the pond, respectively. A Cartesian coordinate system is constructed with its origin sitting at point $A$. The $x$ and $y$ axes are in alignment with the longitudinal and the transverse sides of the pond, and the $z$ axis is pointing positively upwards.

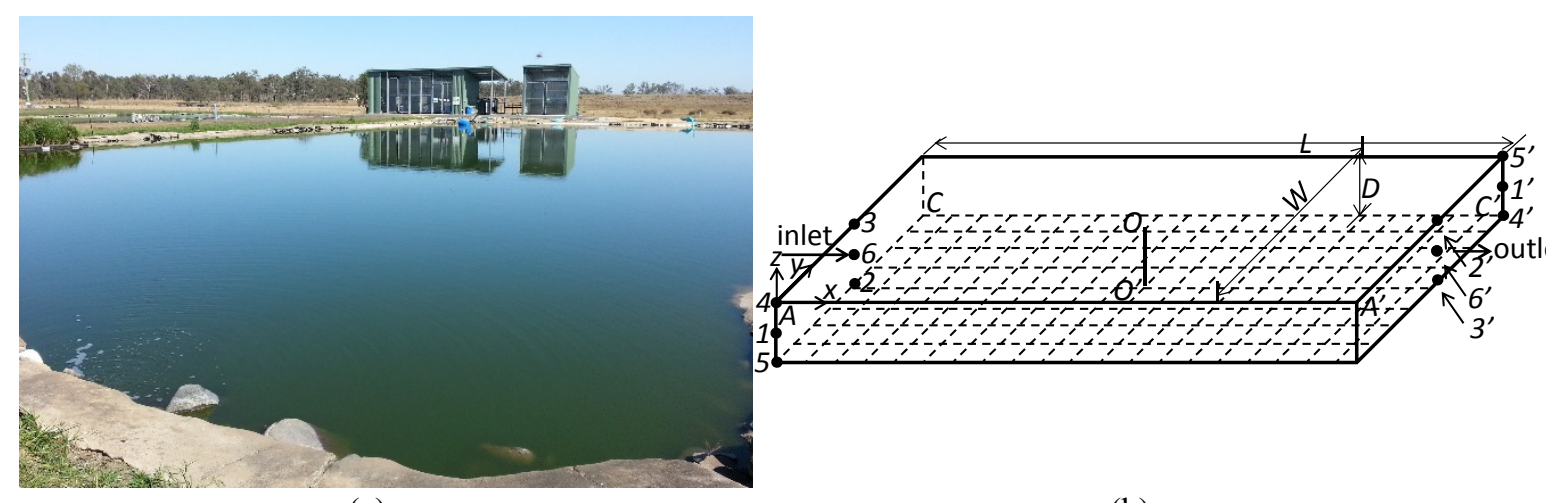

(a)

(b)

Figure 1. Illustration of a typical WSP: (a) field prototype and (b) geometrical model (reproduced from Li et al., 2013).

\subsection{Governing equations}

In three dimensions, the governing equations of the flow in a WSP are to address mass conservation, momentum conservation and energy conservation (Scientific Documentation, MIKE 3 Flow Model, Hydrodynamic Module, 2012): 
Li et al., Improving hydrodynamic performance of waste stabilisation ponds using three-dimensional numerical models

$$
\begin{gathered}
\frac{1}{\rho c_{s}^{2}} \frac{\partial P}{\partial t}+\frac{\partial u_{j}}{\partial x_{j}}=S \\
\frac{\partial u_{i}}{\partial t}+\frac{\partial\left(u_{i} u_{j}\right)}{\partial x_{j}}+2 \Omega_{i j} u_{j}=-\frac{1}{\rho} \frac{\partial P}{\partial x_{i}}+g_{i}+\frac{\partial}{\partial x_{j}}\left(v_{T}\left(\frac{\partial u_{i}}{\partial x_{j}}+\frac{\partial u_{j}}{\partial x_{i}}\right)-\frac{2}{3} \delta_{i j} k\right)+u_{i} S
\end{gathered}
$$

The transport equation in a WSP can be described by:

$$
\frac{\partial C}{\partial t}+\frac{\partial}{\partial x_{j}}\left(C u_{j}\right)=\frac{\partial}{\partial x_{j}}\left(D_{j} \frac{\partial C}{\partial x_{j}}\right)+S
$$

The physical significance of the symbols in (1) to (3) remains the same as explained in Li et al. (2013).

\subsection{Boundary and initial conditions}

(1) to (3) are to be solved under specific conditions at both open and closed boundaries: the free open surface $z=\eta$ ( $\eta$ is the surface elevation) is subject to the atmospheric pressure as well as the wind shear stress. The pond bed floor $z=-d$ ( $d$ is the still water depth) is subject to bed resistance.

At pond side walls, i.e. $x=0, x=L, y=0$ and $y=W$ in Figure 1 (b) except the inlet and outlet locations, a nonslip boundary condition is enforced and normal fluxes for all variables are zero.

At the inlet $\left(x_{i n}, y_{i n}, z_{i n}\right)$, both volumetric flow rate $Q$ and velocity $U$ are specified for the influent discharged into the ambient pond water, as well as influent properties, denoted as $C$ herein, such as temperature and/or pollutant concentration:

$$
Q_{\text {in }}=Q_{I N}(t), U_{i n}=U_{I N}(t), C_{i n}=C_{I N}(t)
$$

At the outlet $\left(x_{\text {out }}, y_{\text {out }}, z_{\text {out }}\right.$ ), volumetric flow rate $Q$ is enforced for the effluent discharged out of the pond:

$$
Q_{\text {out }}=Q_{\text {OUT }}(t)
$$

The solution of (1) to (3) is also subject to initial conditions in terms of flow velocity, pressure (or surface elevation), and temperature and/or pollutant concentration within the pond.

$$
\left.U(x, y, z, t)\right|_{t=0}=U_{0},\left.p(x, y, z, t)\right|_{t=0}=p_{0},\left.C(x, y, z, t)\right|_{t=0}=C_{0}
$$

\section{MODEL DEVELOPMENT}

The software package MIKE 3 developed by Danish Hydraulic Institute (DHI) is employed as the modelling tool. The model uses the Finite Difference Method (FDM) to solve the governing equations subjected to boundary and initial conditions in the spatial and temporal domains. For the geometric model illustrated in Figure 1 (b), a structured computational grid is applied to the bottom floor of the pond. The grid is then projected in the vertical $(z)$ direction throughout the pond depth. In the model, features such as surface elevation, bed resistance, wind conditions and inlet and outlet conditions are specified, corresponding to the boundary conditions illustrated in Section 2.3. Turbulence mode is also examined in the modelling process.

To examine the performance of the proposed model in terms of its convergence behaviour and validity, the wind driven set-up and the velocity field in a pond were studied and the results agreed well with empirical solutions. Details of model verification and convergence analysis of the benchmark example can be found in Li et al. (2013). The example demonstrates the credibility of the proposed model, and suggests a grid size of $\Delta x=1 \mathrm{~m}, \Delta y=1 \mathrm{~m}$, with 7 layers in the vertical direction as the optimal grid resolution for subsequent analyses.

\section{WSP HYDRODYNAMIC BEHAVIOUR}

One of the most representative characteristics of WSP hydrodynamics is the hydraulic retention time. A theoretical retention time $T_{\text {theor }}$ is the ratio of the pond water volume to the pond inflow rate. In reality, the retention time analysis is often conducted by injecting a certain amount of tracer into the pond, and tracer concentration at the inlet and the outlet is monitored, as seen in Figure 2. Using $C(t)$ to denote solely the outlet concentration, a retention time distribution function $E(t)$ is calculated as: 
Li et al., Improving hydrodynamic performance of waste stabilisation ponds using three-dimensional numerical models

$$
E(t)=\frac{Q_{i n}(t) C(t)}{\int_{0}^{\infty} Q_{i n}(t) C(t) d t}
$$

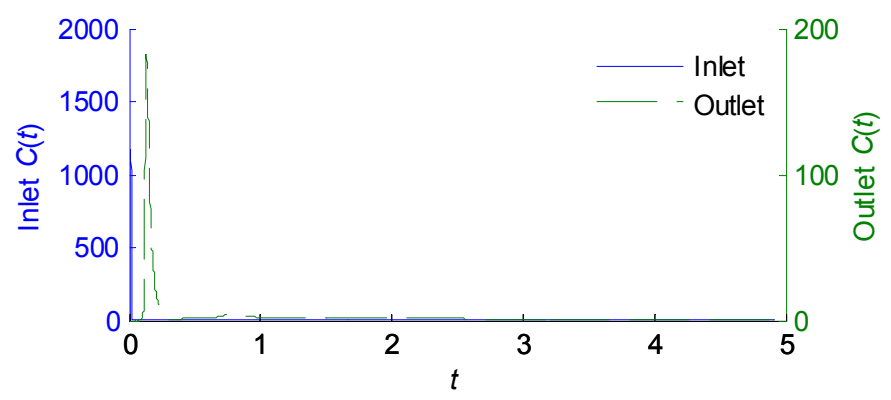

Figure 2. Tracer concentration variation with respect to time at the inlet and outlet.

The product of $E(t)$ and $d t$ quantitatively describes the portion of tracer particles have spent a period of time $d t$ before exiting the pond. This is expressed by the cumulative distribution function $F(t)$, which is formulated as:

$$
F(t)=\int_{0}^{t} E(t) d t
$$

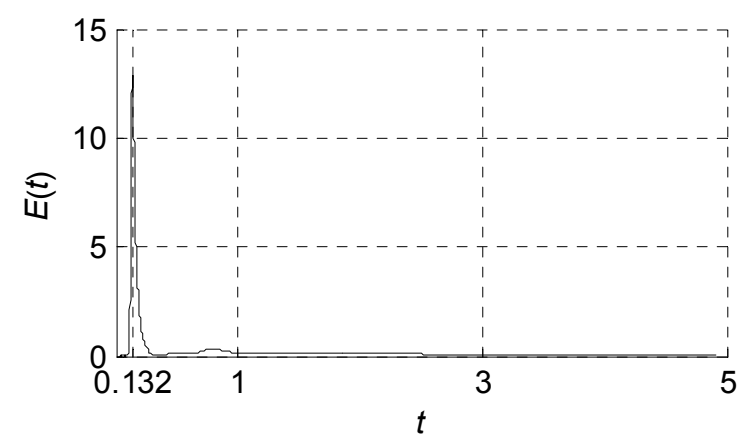

(a)

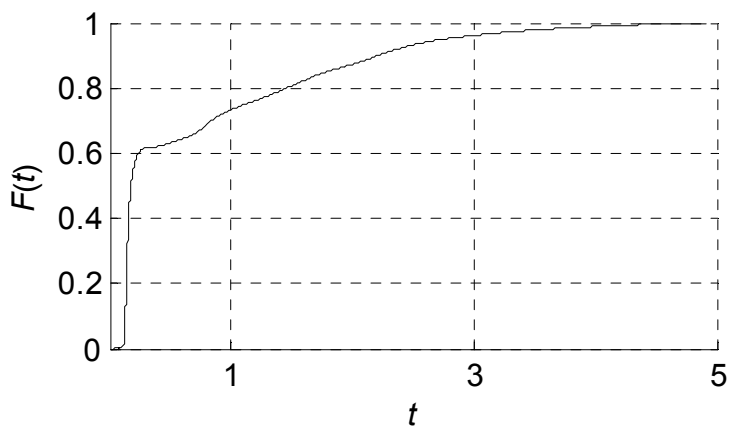

(b)

Figure 3. Retention time analysis: (a) $E(t)$ function and (b) $F(t)$ function.

A typical example of $E(t)$ and $F(t)$ curves is illustrated in Figure 3. They are subsequently used to derive other measures to evaluate WSP hydrodynamic performance, namely:

- $t_{16}, t_{\mathrm{p}}$ (Persson, 2000): represent the time for the passage of the $16^{\text {th }}$ percentile and the highest level of concentration of the tracer through the outlet, respectively;

- Mean residence time $t_{\mathrm{m}}$ (Fogler, 1992): calculated as the first moment of the $E(t)$ function. It measures the average time tracer particles spend in a WSP before exit:

$$
t_{m}=\int_{0}^{\infty} t E(t) d t
$$

- Variance $\sigma^{2}$ (Fogler, 1992): an indication of the 'spread' of $E(t)$ curve. The greater the value is, the greater the distribution's spread is:

$$
\sigma^{2}=\int_{0}^{\infty}\left(t-t_{m}\right)^{2} E(t) d t
$$

- Dead space parameter $V_{d}$ (Mangelso and Watters, 1972): a measure of the amount of pond volume where mixing is less than desirable:

$$
V_{d}=1-t_{m} / T_{\text {theor }}
$$

- Deviation from plug-flow parameter $\bar{\theta}_{p f}$ (Watters et al., 1973): $\bar{\theta}_{p f} \rightarrow 0$ if the flow approaches ideal plug flow:

$$
\bar{\theta}_{p f}=T_{\text {theor }}-\int_{0}^{T_{\text {theor }}} t E(t) d t / \int_{0}^{T_{\text {theor }}} E(t) d t
$$


Li et al., Improving hydrodynamic performance of waste stabilisation ponds using three-dimensional numerical models

- Dispersion number $d$ (Thackston et al., 1987): $d=0$ suggests the plug flow condition and $d \rightarrow \infty$ indicates the completely mixed flow condition:

$$
d=\sigma^{2} / t_{m}^{2}
$$

- Number of CSTRs (continuously-stirred reaction tank) in series $N$ (Fogler, 1992): $N=1$ for continuously stirred flow and $N \rightarrow \infty$ if the flow approaches plug flow:

$$
N=\left(T_{\text {theor }} / \sigma\right)^{2}
$$

- Short-circuiting quotient $S$ (Persson, 2000): smaller $S$ values correspond to severer short circuiting:

$$
S=t_{16} / T_{\text {theor }}
$$

- Hydraulic efficiency $\lambda$ (Persson et al., 1999): a measure of hydraulic conditions of a WSP:

$$
\lambda=t_{p} / T_{\text {theor }}
$$

\section{RETROFITTING DESIGN}

A basic pond case is employed herein to illustrate the retrofitting design. The pond entity associated with the case is featured by an $L / W=2.5$ with $L=50 \mathrm{~m}$ and $W=20 \mathrm{~m}$; the pond inlet and outlet are directly opposite to each other and positioned at the centre of pond side walls $A C$ and $A^{\prime} C^{\prime}$; the inflow direction is $0^{\circ}$; the pond depth is $1.5 \mathrm{~m}$; influent conditions are described with the inflow rate assigned as $Q_{i n}=0.005 \mathrm{~m}^{3} / \mathrm{s}$, and the inflow velocity $U_{\text {in }}=0.01 \mathrm{~m} / \mathrm{s}$.

The most common way of retrofitting a WSP is to place baffles in a pond. Baffles are vertical walls to direct water flow through designated paths to increase the residence time of wastewater. They have gradually become an essential element of WSP constructions due to their well-recognised function in improving the hydraulic and overall treatment efficiency of WSPs. The significant improvement of WSP treatment efficiency by installing baffles leads to an impression that it would be wrong not to baffle WSPs (Mara, 2009).

Previous studies (Watters et al., 1973) have identified two factors governing the design of baffles in a WSP, i.e., the ratio of baffle length $L_{b}$ to the width of the pond $W: L_{b} / W$, and the ratio of baffle spacing $\Delta_{b}$ to the length of the pond $L: \Delta_{b} / L$. According to previous experience (Watters et al., 1973), to retrofit the design of the

\begin{tabular}{|c|c|c|c|}
\hline Case & Layou & $L_{b} / W$ & $\Delta_{b} / L$ \\
\hline 1 & & $70 \%$ & $1 / 7$ \\
\hline 2 & & $50 \%$ & $1 / 5$ \\
\hline 3 & & $50 \%$ & $1 / 7$ \\
\hline 4 & & $70 \%$ & $1 / 5$ \\
\hline
\end{tabular}
basic case in this study, four different baffle layouts were tested varying $L_{b} / W$ between $70 \%$ and $50 \%$ and $\Delta_{b} / L$ between 1/7 and 1/5, as shown in Table 1.

Table 1. Retrofitting baffle design

For ease of comparison, hydraulic measures of both the non-baffled pond and the four baffled ponds are tabulated in Table 2. It can be seen that baffled ponds shown an overall increase in the hydraulic efficiency compared with the non-baffled pond. All temporal factors $t_{16}, t_{p}$ and $t_{m}$ have increased due to the channelling effect from baffles. The volume of stagnant zones is reduced and the flow regime is more like a plug flow as shown in the decreased $d$ and $\bar{\theta}_{p f}$ and the increased $N$. The degree of short-circuiting is lessened as noticed in the increasing $S$ value. Overall, the hydraulic efficiency is improved from 0.31 to $0.50 \sim 0.62$ compared to the non-baffled pond. 
Li et al., Improving hydrodynamic performance of waste stabilisation ponds using three-dimensional numerical models

Table 2. Hydrodynamic measures of baffled ponds

\begin{tabular}{|l|l|l|l|l|l|l|l|l|l|l|l|}
\hline Case & $t_{16}$ & $t_{p}$ & $t_{m}$ & $t_{85}$ & $\sigma^{2}$ & $V_{d}$ & $\bar{\theta}_{p f}$ & $d$ & $N$ & $S$ & $\lambda$ \\
\hline No-baffle & 0.31 & 0.31 & 0.85 & 1.77 & 0.89 & 0.15 & 0.59 & 1.23 & 1.11 & 0.31 & 0.31 \\
\hline 1 & 0.62 & 0.62 & 1.05 & 1.55 & 0.40 & 0.01 & 0.27 & 0.36 & 2.53 & 0.62 & 0.62 \\
\hline 2 & 0.49 & 0.49 & 0.99 & 1.58 & 0.62 & 0.01 & 0.39 & 0.64 & 1.61 & 0.49 & 0.49 \\
\hline 3 & 0.50 & 0.50 & 1.05 & 1.77 & 0.61 & 0.01 & 0.38 & 0.55 & 1.64 & 0.50 & 0.50 \\
\hline 4 & 0.49 & 0.49 & 0.99 & 1.60 & 0.61 & 0.01 & 0.40 & 0.63 & 1.64 & 0.49 & 0.49 \\
\hline
\end{tabular}

Results of the tested four cases have shown that case 1 with $L_{b} / W=70 \%$ and $\Delta_{b} / L=1 / 7$ presents the best hydraulic performance by improving the efficiency of the pond from 0.31 to 0.62 . Placing baffles creates compartments in the pond, and direct wastewater to flow in a designated path, as shown in Figure 4. These compartments are parallel and connected, and if unfolded, they form a rectangular pond with a rather large $L / W$ ratio. The layout in case 1 generates a pond with an equivalent $L / W=20$, and is considered the optimal retrofitting design for the basic case amongst the four.

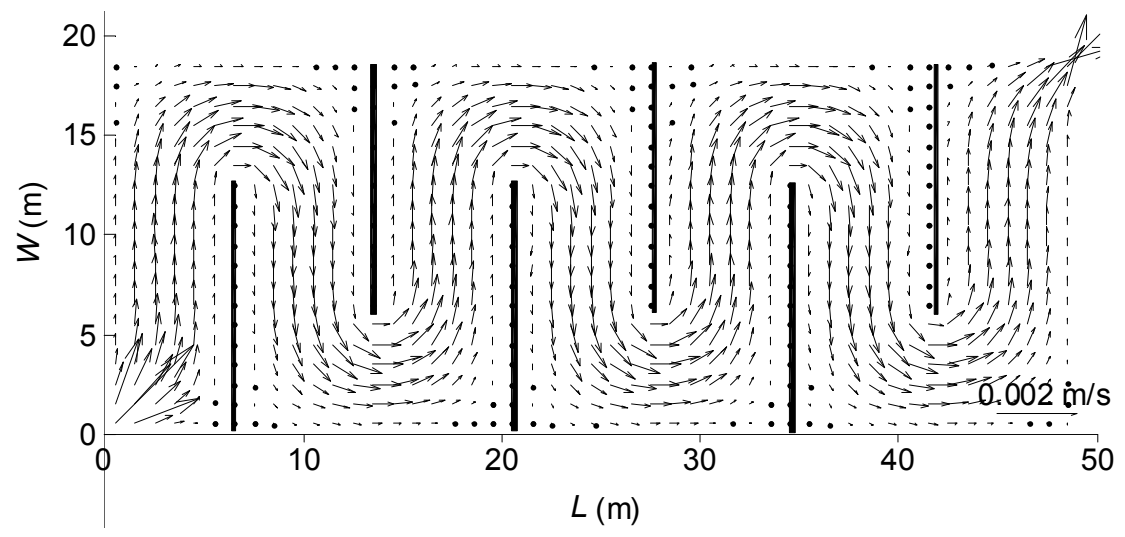

Figure 4. Velocity vector plot at the horizontal plane at pond middle depth for baffled pond case 1.

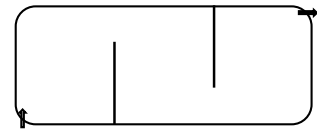

2 baffles

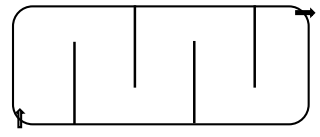

4 baffles

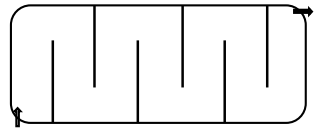

6 baffles

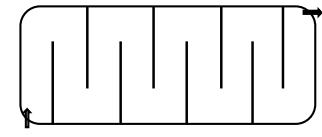

8 baffles

Figure 5. Retrofitting design with different number of baffles in the pond.

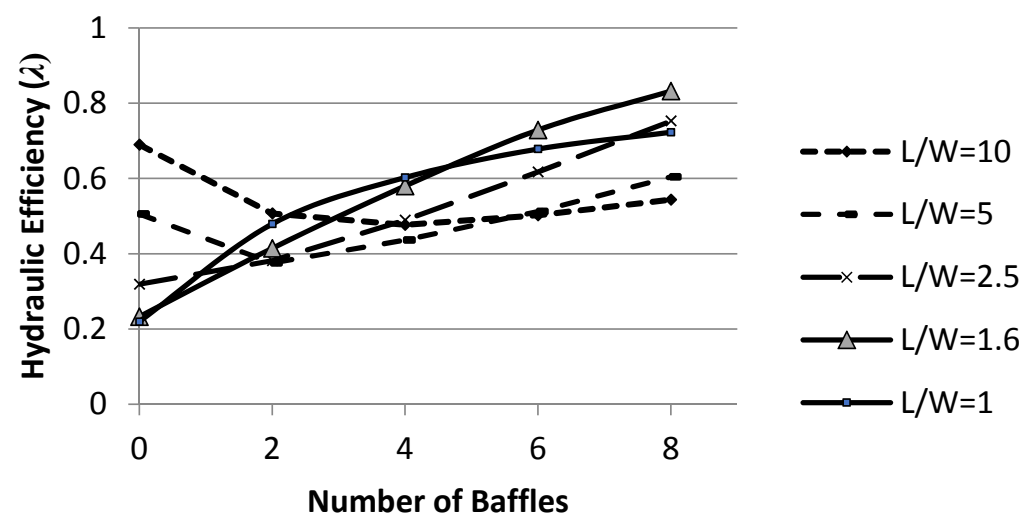

Figure 6. Hydraulic efficiency vs. number of baffles for varying pong $L / W$ ratio.

It is believed that with different pond geometric configurations, the retrofitting baffling design would be different. To offer generalised design guidance, retrofitting schemes for ponds with varying length-to-width ratio were investigated. For $L / W$ ratio ranging as: $10,5,2.5,1.6,1$, different numbers of baffles $(2,4,6$ and 8$)$ were placed in the pond as shown in Figure 5. The baffles are of a length of $70 \%$ of the pond width. The 
Li et al., Improving hydrodynamic performance of waste stabilisation ponds using three-dimensional numerical models

hydraulic efficiency was plotted against the number of baffles for each $L / W$ ratio in Figure 6. Ponds with a smaller $L / W$ ratio $(1,1.6$ and 2.5$)$ benefit significantly from the baffling effect. The hydraulic efficiency can be improved up to 0.83 for ponds with $L / W=1.6$ retrofitted with 8 baffles, whereas a non-baffled pond only has a hydraulic efficiency of 0.23 . On the other hand, ponds with a larger $L / W$ ratio (5 and 10$)$ don't necessarily benefit from retrofitting baffles. Therefore, it is suggested that pond be designed with reasonable $L / W$ ratio combined with appropriate number of baffles to achieve optimised hydrodynamic performance. This study presented herein did not include the effects of wind or thermal stratification, which may alter the conclusions accordingly.

\section{CONCLUSIONS}

This study employed a validated three-dimensional numerical model to investigate methods to improve WSP hydrodynamic performance. The retrofitting scheme was proposed by placing baffles in a pond with different geometric ratios: the ratio of baffle length $L_{b}$ to the width of the pond $W: L_{b} / W$, and the ratio of baffle spacing $\Delta_{b}$ to the length of the pond $L: \Delta_{b} / L$. For generalised design guidance, baffles positively contribute to the hydraulic efficiency for ponds with a relatively small $L / W$ ratio. Placing 8 baffles in a pond with $L / W=1.6$ results in a $\lambda=0.83$ as oppose to $\lambda=0.23$ if the pond is not baffled. However, ponds do not benefit from retrofitting baffles if their $L / W$ ratios are large. Further studies in terms of the interrelated effects of multiple factors on pond efficiency, such as wind and temperature are in progress.

\section{REFERENCES}

Abbas, H., Nasr, R., Seif, H., 2006. Study of waste stabilization pond geometry for the wastewater treatment efficiency. Ecological Engineering 28 (1), 25-34.

Alvarado, A., Vedantam, S., Durazno, G., Nopens, I., 2011. Hydraulic assessment of waste stabilization ponds: Comparison of computational fluid dynamics simulations against tracer data.

Badrot-Nico, F., Guinot, V., Brissaud, F., 2009. Fluid flow pattern and water residence time in waste stabilisation ponds. Water Science and Technology 59 (6), 1061-1068.

Fares, Y.R., 1993. Circulation pattern in long narrow lakes based on shallow water equations. Advances in Hydro-science \& Engineering (ed SSY Wang), 1142-1147.

Fares, Y.R., Lloyd, B.J., 1995. Wind effects on residence time in waste stabilisation lagoons, The congress international association for hydraulic research, pp. 205-211.

Fogler, H.S., 1992. Elements of chemical reaction engineering. Prentice-Hall.

Li, M., Zhang, H., Lemckert, C., Lu, Z., Lei, L.-M., Stratton, H., 2013. Three-dimensional Investigation of Retention Time Distribution of Waste Stabilisation Ponds, 20th International Congress on Modelling and Simulation (MODSIM2013), Adelaide, Australia.

Mangelso, K.A., Watters, G.Z., 1972. Treatment Efficiency of Waste Stabilization Ponds. Journal of the Sanitary Engineering Division-Asce 98 (Nsa2), 407-\&.

Persson, J., 2000. The hydraulic performance of ponds of various layouts. Urban Water 2 (3), 243-250.

Persson, J., Somes, N., Wong, T., 1999. Hydraulics efficiency of constructed wetlands and ponds. Water Science \& Technology 40 (3), 291-300.

Salter, H.E., Ta, C.T., Williams, S.C., 2000. Three-dimensional computational fluid dynamic modelling of a facultative lagoon. Water Science and Technology 42 (10-11), 335-342.

Sweeney, D., Nixon, J., Cromar, N.J., Fallowfield, H.J., 2005. Profiling and modelling of thermal changes in a large waste stabilisation pond. Water science and technology: a journal of the International Association on Water Pollution Research 51 (12), 163.

Thackston, E.L., Shields Jr, F.D., Schroeder, P.R., 1987. Residence time distributions of shallow basins. Journal of Environmental Engineering 113 (6), 1319-1332.

Watters, G.Z., Mangelson, K.A., George, R.L., Research, U.S.O.o.W.R., 1973. The Hydraulics of Waste Stabilization Ponds. Utah Water Research Laboratory.

Wood, M.G., Greenfield, P.F., Howes, T., Johns, M.R., Keller, J., 1995. Computational Fluid Dynamic Modeling of Waste-Water Ponds to Improve Design. Water Science and Technology 31 (12), 111-118. 